\title{
En gravid kvinne med oppkast og pustebesvær
}

\author{
Kvalme og oppkast er en vanlig og oftest en ufarlig problemstilling for \\ kvinner i tidlig graviditet. En sjelden gang er innleggelse for støttende \\ behandling nødvendig. Noen ganger kan graviditeten maskere pasien- \\ tens egentlige problem.
}

En tidligere frisk kvinne i 40-årene, gravid i uke 15 (para 1, ukomplisert, sju år tidligere), var innlagt $i$ sykehus med slapphet, kvalme, oppkast og ketonuri. Tilstanden ble oppfattet som hyperemesis gravidarum. Hun ble utskrevet etter to dager $i$ bra form etter behandling med væske og antiemetika.

Betegnelsen «hyperemesis gravidarum» blir ofte brukt om vedvarende kvalme, brekninger og oppkast før uke 20 i svangerskapet. Tilstanden gir dehydrering, elektrolyttforstyrrelser, vekttap og nedsatt allmenntilstand. Median debut er rundt svangerskapsuke 8-9, noe tidligere enn i dette tilfellet.

To dager etter utskrivningen ble vakthavende primærlege og ambulanse tilkalt til kvinnen, som akutt hadde fått tung og surklete respirasjon. Luftambulanse ble varslet. De møtte en kvinne sittende på båre med takypné (respirasjonsfrekvens 30-35) og bruk av aksessorisk respirasjonsmuskulatur. Hun hadde lette brystsmerter og dyspné, men ingen stridor eller andre symptomer. $\mathrm{O}_{2}$-saturasjonen var $90 \%$ med tilførsel av $121 \mathrm{O}_{2}$ per minutt.

Differensialdiagnoser hos gravide med akutt pustebesvær inkluderer pneumoni, lungeødem og lunge-/fostervannsembolisme. I tillegg må kardial årsak og hypertensiv svangerskapskomplikasjon vurderes hos sirkulatorisk påvirkede pasienter. Akutt sykdom kan også få et mer dramatisk forløp hos gravide på grunn av de fysiologiske endringene (mindre reserver på grunn av økt hjerteminuttvolum, økt blodvolum og redusert lungekapasitet) som inntrer i første og tidlig $\mathrm{i}$ annet trimester.

Dyspné og hypoksi ga mistanke om lungeembolisme, og det ble gitt lavfraksjonert heparin (Klexane) før transport i ambulansehelikopter til sykehus. Kvinnen utviklet under transporten akutt respiratorisk svikt lapnél, derfor ble det gjort luftveisintubasjon og gitt trombolytisk behandling med tenecteplase (Metalyse).

Ved ankomst til sykehuset var hun afebril, med blodtrykk 103/55 mm Hg, puls 61 og normalt EKG, men med lett respiratorisk acidose. Alvorlig lungeembolisme og/eller kardial årsak ble avkreftet ekkokardiografisk 12 minutter etter at trombolytisk behandling var gitt. Fosteret var vitalt, og det ble ikke observert vaginal blødning.

Fatal lungeembolisme er en av de viktigste årsakene til maternell død $(1,2)$. Vår pasient manglet imidlertid de sterkeste risikofaktorene - tidligere spontan venøs tromboembolisme og trombofili. Graviditet er en risikofaktor i seg selv, med hyperkoagulabilitet, venøs stase og, særlig under fødselen, vaskulær skade (Virchows triade).

Blodprøver, inkludert troponiner og stoffskifte, viste ved innkomst nærmest normale funn, videre spesifisert for natrium 136 mmol/l (137- $145 \mathrm{mmol} / \mathrm{l})$, kalium 3,8 $\mathrm{mmol} / \mathrm{l}$ (3,5-4,4 mmol/l), albumin $28 \mathrm{~g} / \mathrm{l}(36-45 \mathrm{~g} / \mathrm{l})$. $D$-dimer var høyt over referanseområdet for ikke-gravide med > 4,0 mg/l (0,0-0,4 mg/l).

Den respiratoriske acidosen ble normalisert innen 60 minutter. Kvinnen ble etter kort tid ekstubert og var respiratorisk stabil etter dette. Gjentatte røntgen thorax innkomstdagen viste imidlertid vedvarende luft i mediastinum, og tentativ diagnose ble pneumomediastinum (fig 1).

Pneumomediastinum forårsakes av eksterne/interne traumer mot thorax/intratorakale organer. Det kan være en rift i en bronkie, f.eks. etter intubering. Det kan også oppstå etter ruptur av alveoler grunnet forhøyet trykk ved astmaanfall eller oppkast hvilket virket mer trolig for vår pasient.

Sjeldnere er oesophagusruptur årsaken, da oftest iatrogent, men også oppkastbetinget (3). Ofte vil man da ha pleuravæske med eller uten pneumothorax samt typisk subkutant emfysem, noe vår pasient ikke hadde.

Røntgen thorax viste i løpet av to døgn tilbakegang av pneumomediastinum. Kvinnen utviklet ikke mediastinitt, det var nær normale blodprøver som leukocytter 5,9-10,6 $10^{9} / \mathrm{l}$ (3,5-11,0 $\left.\cdot 10^{9} / \mathrm{l}\right)$ og CRP $10 \mathrm{mg} / \mathrm{l}(0-6 \mathrm{mg} / \mathrm{l})$, og afebrilitet $i$ hele forløpet.

Videre oppfølging av hyperemesis gravidarum og ernæringsproblematikken foregikk på kvinneklinikken. Hun hadde fortsatt ketonuri $(3+)$ og fikk i tillegg til parenteral

\author{
Håvard Hatle \\ havarhat@gmail.com \\ Kvinneklinikken \\ Ålesund sjukehus \\ og \\ Barne- og ungdomsklinikken \\ St. Olavs hospital
}

Boris Marcus Erwied

Anestesiavdelingen

Inge Lode

Radiologisk avdeling

Åse Roald Sandvik

Kvinneklinikken

Ålesund sjukehus

Jan Gunnar Hatlebakk

Gastroenterologisk seksjon

Medisinsk avdeling

\section{Kjell Øvrebø}

Gastroenterologisk seksjon

Kirurgisk avdeling

Haukeland universitetssykehus

Dag Arne Lihaug Hoff

Seksjon for mage-tarmsjukdommar

Medisinsk avdeling

Ålesund sjukehus

> Se kommentar side 430 
ernæring intravenøs væske tilsatt antiemetika, med god effekt.

Oesophagusruptur og pneumomediastinum er sjeldne, men livstruende tilstander i graviditeten. De oppstår hyppigst under fødselens utdrivningsfase grunnet intratorakal trykkøkning. Uttalte brekninger kan også føre til ruptur av oesophagus i forbindelse med graviditet (4). Ved oppkastrelatert oesophagusruptur må antibiotikabehandling og umiddelbar kirurgisk behandling iverksettes. Også ved tidlig kirurgi er det rapportert død hos omtrent en tredel (5).

Ved pneumomediastinum med alveolært eller bronkogent utgangspunkt er tett observasjon ofte tilstrekkelig (6). Vi fant det trygt å observere pasienten, da hun klinisk og paraklinisk var nær upåvirket etter den korte intubasjonen.

I samtale kom det frem at pasienten tidligere hadde hatt liknende forbigående episoder med pustebesvær. I forkant av den aktuelle hendelsen hadde hun drukket saft, med påfølgende hosteanfall og følelse av aspirasjon. Hun kunne videre fortelle om flere år med svelgevansker, regurgitasjon av føde, følelse av å få maten i vrangstrupen og gjentatte episoder med oppkast.

De siste to årene hadde hun endret sovestilling til mer sittende posisjon. Hun beskrev et vekttap på 10-15 kg i løpet av flere år, mest det siste halvåret. Plagene hadde startet altså før og uavhengig av svangerskapet. I tillegg la vi merke til at hun på sengeposten satt og leste i matmagasiner, hvilket syntes svært uvanlig for en pasient med svangerskapskvalme.

Vedvarende problemer med å spise seks dager ut i forløpet fordret gastroskopi med primærhensikten nedlegging av nasojejunal ernæringssonde. Endoskopisk var oesophagus dilatert, oesophagus/ventrikkel inneholdt væske/matrester, men ingen ruptur ble sett. Vi fikk plassert ernæringssonde, men grunnet den dårlige oversikten ble sondeplasseringen kontrollert radiologisk. Den viste at sonden lå over diafragma i en påfallende bred oesophagus.

Vi mistenkte nå oesophagusakalasi. Luften som var projisert over mediastinum ved innkomst (fig 1), var sannsynligvis luft $i$ en dilatert oesophaugus og ikke uttrykk for pneumomediastinum, som først antatt. MR oesophagus viste slynget og dilatert $1>6 \mathrm{~cm}$ proksimalt) oesophagus med innhold, stenose ved overgangen til ventrikkel og små bilaterale lungefortetninger. Det var bildemessig ikke mistanke om stenoserende malignitet (fig 2).

Akalasi kan med kompresjon av trachea gi akutt øvre luftveisobstruksjon (7). Aspira-

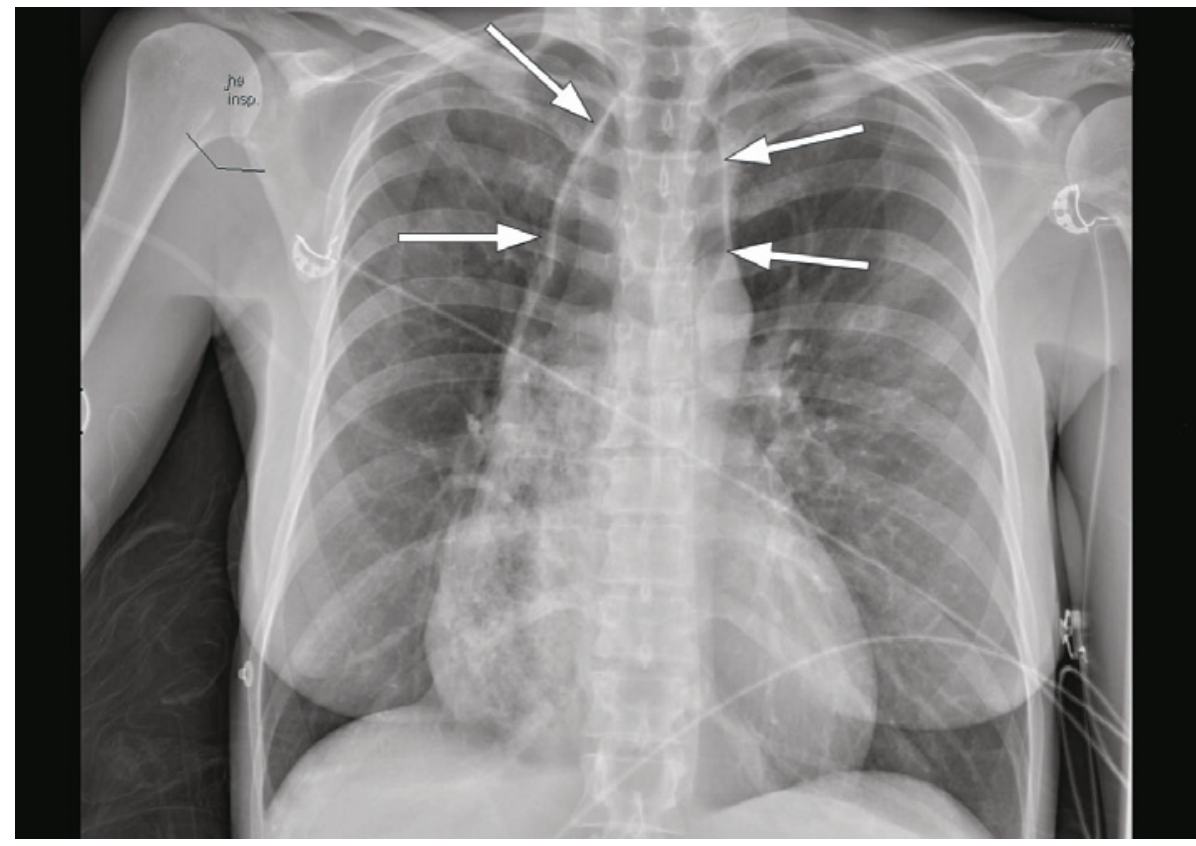

Figur 1 Røntgen thorax, halvt sittende frontbilde innleggelsesdagen, viser luft projisert over øvre mediastinum. Merk at luften ikke helt følger konturene til mediastinum

sjon til lungene av innhold i oesophagus kan også oppstå. Umiddelbar nedlegging av peroral sonde (grov ventrikkelsonde), eventuelt en mindre nasoøsofageal sonde med forsøk på dekompresjon av en kraftig dilatert oesophagus, kan være livreddende (8).

Pasienten ble 11 dager ut i forløpet flyttet til medisinsk avdeling. Ved regastroskopi evakuerte man først > $600 \mathrm{ml}$ flytende innhold (trass i null per os i fem dager). Oesophagus var kraftig utvidet, høyredevierende og uten propulsiv bevegelse. Overgangen til ventrikkelen var vanskelig å lokalisere, men endoskopisk uproblematisk å intubere. Ventrikkelen var tom. Forsøk på manometri ble mislykket.

Akalasi («svikt i relaksasjon») er en tilstand med dysmotilitet i spiserøret. Typisk har nedre oesophagussphincter økt hvile- og relaksasjonstrykk. Ved sykdomsprogrediering dilateres oesophagus, og dens peristaltikk og evne til tømming avtar.

Hovedsymptomet er gradvis økende svelgevansker, det gjelder både fast og flytende føde. Andre symptomer er følelse av oppfylling i brystet (som avtar ved dilatasjon), regurgitasjon av matrester og vekttap. Ved mistanke blir endoskopi utført, dernest røntgen oesophagus med kontrast og videoopptak, til slutt en bekreftende manometri. Kontrastundersøkelse ble ikke gjort hos vår pasient på grunn av graviditeten.

Med endoskopisk teknikk ble en nasojejunal ernæringssonde lagt ned, og en kombina- sjon av enteral og parenteral ernæring i opptrappende doser ble startet. Pasienten ble overført til universitetssykehus for behandling av akalasi 17 dager etter den akutte hendelsen.

En betydelig diagnostisk forsinkelse er typisk ved akalasi. Pasienten har i gjennomsnitt hatt svelgevansker $\mathrm{i}$ fem år og flere leger har vært konsultert. Forsinkelsen har som oftest bakgrunn i feiltolking av tilstandens typiske presentasjon (9).

Hos vår pasient ble både det kliniske bildet, utredning og behandling av komplisert hennes graviditet. Da de vanligste behandlingsalternativene (ballongdilatasjon og kirurgisk myotomi) ville medføre en betydelig risiko grunnet narkose, kirurgi og strålebelastning, ble det i samråd med kvinnen avgjort ikke å gjennomføre dette under svangerskapet.

Vi gjorde allikevel et terapiforsøk i graviditetsuke 18, da vi endoskopisk plasserte en selvekspanderende stent gjennom spiserørventrikkel-overgangen. Den skulle ligge $i$ åtte uker og så fjernes, men sju dager etter prosedyren fikk kvinnen på ny akutt dyspné og stridor etter inntak av kjeks og most mat.

Vi fant stenten dislosert til øvre oesphagussphincter, der den medførte kompresjon av trachea. Stenten var full av mat, men ble ukomplisert fjernet endoskopisk.

Patogenesen bak akalasi omfatter blant annet tap av nerveceller, som igjen medfører et misforhold mellom relaksasjon og kontraksjon 
av glatte muskelceller i oesophagus. Tilstanden har en insidens på 0,5 og en prevalens på 10 per 100 000, likt for begge kjønn (10). Behandlingen er ikke kurativ, målet er å lindre svelgevansker, bedre ernæringsstatusen og motvirke videre dilatasjon. Man kan avvente behandling, men hos eldre og svekkede pasienter kan for eksempel gjentatte botulinumtoksininjeksjoner brukes.

Metodene ballongdilatasjon og laparoskopisk myotomi foretrekkes, begge med varig og lik effekt etter to år $(10,11)$. Stenting av oesophagus-ventrikkel-overgangen er nylig rapportert å kunne ha varig effekt og være mer effektivt enn ballongdilatasjon(12).

Ytterligere behandlingsmessige tiltak var nå ikke aktuelt. Nasojejunal ernæringssonde ble skiftet fem ganger lomtrent hver 4. -5 . ukel før termin. Dette ble utført endoskopisk uten sedasjon. Pasienten klarte å gjennomføre den enterale ernæringen $i$ hjemmet med Fresubin orginal $1500 \mathrm{ml} / \mathrm{d} ø \mathrm{gn}$. Det var problematisk å nå $2000 \mathrm{ml}$, som var målet. Inntil behandling for akalasien etter fødselen fikk hun bare sondeernæring.

Førgravid vekt var $63 \mathrm{~kg}$, det var ingen vektøkning i svangerskapet og hun veide 62 $\mathrm{kg}$ ved innleggelse i graviditetsuke 38. Etter induksjon av fødsel fødte hun et sprekt barn. Det ble underveis gjort vekstkontroller av fosteret, som ved fødselen var undervektig (22\% under normal vekt i forhold til svangerskapslengde).

Det radiologiske bildet viste før terapi en distal oesophagus med et mer konisk utseende (fuglenebb). Etter diskusjon ønsket vi først å forsøke blokking av nedre sphincter med klassisk akalasiballong. Kvinnen har vært observert i 36 uker etter én blokking. Hun spiser normalt og har hatt vektøkning på > $10 \mathrm{~kg}$.

\section{Diskusjon}

Denne pasienthistorien understreker hyperemesis gravidarum som en eksklusjonsdiagnose. Forekomsten av tilstanden angis til $0,3-2 \%$. Etiologien er i hovedsak ukjent, men økt forekomst ved flerlinger, blæremola og jentefoster er sett $(13,14)$. I uttalte tilfeller kan vitaminstilskudd, enteral eller parenteral ernæring bli nødvendig. Det er god prognose med adekvat behandling, ubehandlet kan især vitaminmangel gi alvorlig sykdom.

I svangerskap er risikoen for lungeembolisme høyest rundt tidspunktet for fødselen. Behandlingen ved bekreftet eller sterkt mistenkt lungeembolisme er lavfraksjonert heparin. Ved hemodynamisk påvirkning, som vedvarende arteriell hypotensjon og/eller positiv sjokkindeks, er trombolytisk behandling indisert også i graviditet $(1,15,16)$. Retningslinjene er basert på kasusbeskrivelser.

Verken den eldre streptokinase eller

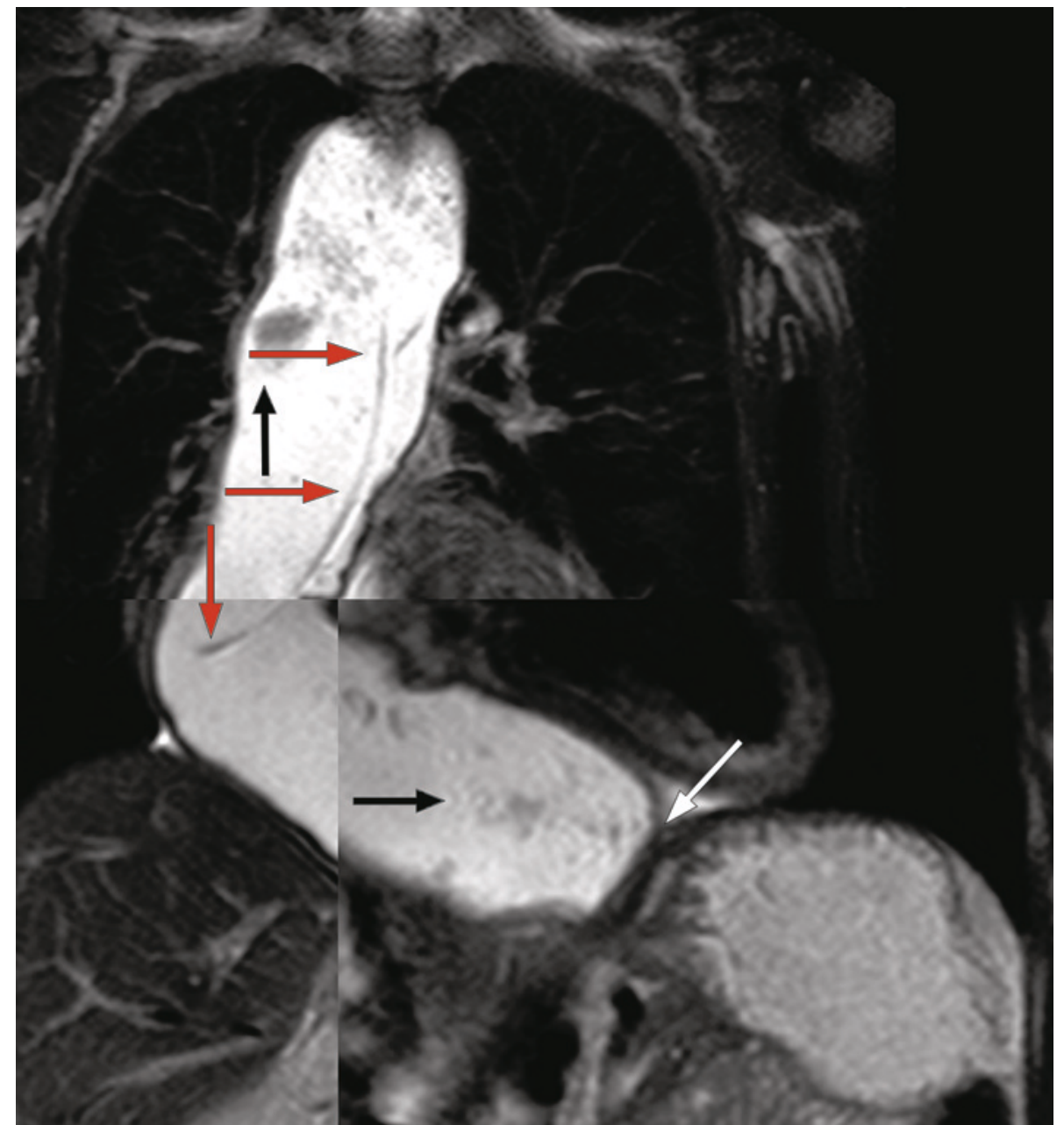

Figur 2 Fusjon av tre forskjellige MR-bilder viser slynget, dilatert oesophagus med matrester (svarte piler), innlagt sonde (røde piler) og stenose (hvit pil) ved overgangen til ventrikkel

dagens mest brukte rekombinant vevsplasminogenaktivator (r-tPA) krysser placenta i signifikant grad. Blødning er observert hos ca. $8 \%$, hyppigst fra genitaltractus (1). Risikoen ved trombolytisk behandling vurderes som akseptabel sett $\mathrm{i}$ forhold til utfallet monoterapi med lavfraksjonert heparin kan gi (1). I en oppsummering fra 2006 om trombolytisk behandling (r-tPA) gitt i svangerskap fant man 28 rapporterte tilfeller (17). Rapporten beskriver to føtale dødsfall $(8 \%)$ hvor kausal sammenheng med behandlingen var sannsynlig, men ikke bevist.

Normalområdet for D-dimerverdien øker progressivt under svangerskapet (39\% relativ økning av gjennomsnittsverdien for hvert trimester), men den negative prediktive verdien er opprettholdt $(15,18)$. Positiv prøve gir mistanke om venetrombose og skal initiere ultralydundersøkelse av dype vener i underekstremitetene, og et positivt funn indikerer antikoagulasjonsbehandling. Ved negativ ultralydundersøkelse, men fortsatt sterk klinisk mistanke om lungeembolisme gir CT-angiografi av thorax lavest stråle- dose, men lungeventilasjons-/perfusjonsscintigrafi er anbefalt om det er tilgjengelig $(15,16)$

Ved behandling av akalasi med dilatasjon blir en ballong lagt gjennom nedre oesophagussphincter og blåst opp ved innsetting av væske/røntgenkontrast. Ofte er flere dilatasjoner nødvendig, vanligvis med økende ballongdiameter. Alvorligste komplikasjon er oesophagusruptur, som er funnet å forekomme hos $1,9 \%$ av pasientene (19).

Standard kirurgisk behandlingsmetode av akalasi er abdominal laparoskopi med myotomi ad modum Heller av nedre oesophagussphincter/proksimale ventrikkel, med fundoplikasjon for å hindre postoperativ gastroøsofageal refluks. Oesophagusperforasjon er vanligste alvorlige komplikasjon (7-15\%) (19).

Det foreligger ikke kontrollerte studier om behandling av akalasi i svangerskapet. I en oppsummering fant man ingen vesentlig påvirkning av føtalt utfall ved tilstanden, men én rapport pekte på malnutrisjon som årsak til et føtalt tap (20). Samme rapport 
viser til vellykkede ballongdilatasjoner både i første og annet trimester. Det er også rapportert vellykket behandling med laparoskopisk myotomi ad modum Heller i annet trimester (21).

Risikoen ved nye svangerskap belyses av en kvinne med gjennomgått myotomi som i påfølgende svangerskap ble innlagt med svær mediastinal herniering av ventrikkel/ tarm. Et slikt brokk kan gi akutt dyspné ved kompresjon og akuttkirurgi kan bli nødvendig, uavhengig av svangerskapsalder (22).

Akutt pustebesvær hos gravide kan by på diagnostiske utfordringer. På mors indikasjon må trombolytisk behandling gis ved mistanke om alvorlig lungeembolisme. Akalasi som årsak til akutt dyspné er sjeldent. Grundig anamnese som verktøy understrekes av vår pasienthistorie, hvor diagnostikken også ble forsinket og behandlingen komplisert fordi hun var gravid.

Pasienten har gitt samtykke til at artikkelen blir publisert.

\section{Håvard Hatle (f. 1984)}

er lege i spesialisering. Ved aktuelle hendelse var han turnuslege ved Kvinneklinikken, Ålesund sjukehus.

Forfatter har fylt ut ICMJE-skjemaet og oppgir ingen interessekonflikter.

\section{Boris Marcus Erwied (f. 1971)}

er spesialist i anestesiologi. Han jobber også ved luftambulansen i Ålesund.

Forfatter har fylt ut ICMJE-skjemaet og oppgir ingen interessekonflikter.

\section{Inge Lode (f. 1959)}

er spesialist i radiologi og overlege.

Forfatter har fylt ut ICMJE-skjemaet og oppgir ingen interessekonflikter.

\section{Åse Roald Sandvik (f. 1971)}

er spesialist i fødselshjelp og kvinnesykdommer og overlege.

Forfatter har fylt ut ICMJE-skjemaet og oppgir ingen interessekonflikter.

\section{Jan Gunnar Hatlebakk (f. 1959)}

er spesialist i indremedisin og i fordøyelsessykdommer og overlege.

Forfatter har fylt ut ICMJE-skjemaet og oppgir ingen interessekonflikter.

\section{Kjell K. Øvrebø (f. 1958)}

er spesialist i generell kirurgi og i gastroenterologisk kirurgi og overlege.

Forfatter har fylt ut ICMJE-skjemaet og oppgir ingen interessekonflikter.

\section{Dag Arne Lihaug Hoff (f. 1965)}

er ph.d. og spesialist i indremedisin og i fordøyelsessykdommer, med særskilt kompetanse i nevrogastroenterologi og motilitet. Han er overlege, forskningsveileder i Helse Møre og Romsdal og sitter i styret for Scandinavian Association of Neurogastroenterology and Motility. Forfatter har fylt ut ICMJE-skjemaet og oppgir ingen interessekonflikter.

\section{Litteratur}

1. Torbicki A, Perrier A, Konstantinides S et al. Guidelines on the diagnosis and management of acute pulmonary embolism: the Task Force for the Diagnosis and Management of Acute Pulmonary Embolism of the European Society of Cardiology (ESC). Eur Heart J 2008; 29: 2276-315.

2. Brown HL, Hiett AK. Deep vein thrombosis and pulmonary embolism in pregnancy: diagnosis, complications, and management. Clin Obstet Gynecol 2010; 53: 345-59.

3. Vang $T$, Våge $V$, Sletteskog N. Boerhaaves syndrom - uvanleg årsak til akutte retrosternale smerter. Tidsskr Nor Lægeforen 2002; 122: 603-4.

4. Liang SG, Ooka F Santo A et al. Pneumomediastinum following esophageal rupture associated with hyperemesis gravidarum. J Obstet Gynaecol Res 2002; 28: 172-5.

5. Gondal G, Johnson E, Johannessen $\mathrm{HO}$ et al. Behandling av oesophagusperforasjoner. Tidsskr Nor Legeforen 2008; 128: 1050-2.

6. Caceres M, Ali SZ, Braud R et al. Spontaneous pneumomediastinum: a comparative study and review of the literature. Ann Thorac Surg 2008; 86: $962-6$.

7. Paulsen V, Syversen T, Kett K. En uvanlig årsak til akutt luftveisobstruksjon. Tidsskr Nor Legeforen 2010; 130: 2241

8. Miyamoto S, Konda Y, Matsui M et al. Acute airway obstruction in a patient with achalasia. Intern Med 2011; 50: 2333-6.

9. Eckardt VF, Köhne U, Junginger T et al. Risk factors for diagnostic delay in achalasia. Dig Dis Sci 1997; 42: 580-5.
10. Richter JE. Achalasia - an update. J Neurogastroenterol Motil 2010; 16: 232-42.

11. Boeckxstaens GE, Annese V, des Varannes SB et al. Pneumatic dilation versus laparoscopic Heller's myotomy for idiopathic achalasia. N Engl J Med 2011; 364: 1807-16

12. Li YD, Tang GY, Cheng YS et al. 13-year follow-up of a prospective comparison of the long-term clinical efficacy of temporary self-expanding metallic stents and pneumatic dilatation for the treatment of achalasia in 120 patients. AJR Am J Roentgenol 2010: 195: 1429-37.

13. Hære IM, Steinbakk A, Vikanes ÅS et al. Hyperemesis gravidarum. I: Bjørge L, Hordnes K, Øian P et al, red. Veileder i Fødselshjelp. 2. utg. Oslo: Norsk Gynekologisk Forening, 2008.

14. Veenendaal MV, van Abeelen AF. Painter RC et al. Consequences of hyperemesis gravidarum for offspring: a systematic review and meta-analysis. BJOG 2011; 118: 1302-13.

15. Regitz-Zagrosek V, Blomstrom Lundqvist C, Borghi $C$ et al. ESC Guidelines on the management of cardiovascular diseases during pregnancy: the Task Force on the Management of Cardiovascular Diseases during Pregnancy of the European Society of Cardiology (ESC). Eur Heart J 2011; 32: 3147-97.

16. Jacobsen AF, Sandset PM. Venous thromboembo lism associated with pregnancy and hormonal therapy. Best Pract Res Clin Haematol 2012; 25: 319-32.

17. Leonhardt G, Gaul C, Nietsch HH et al. Thrombolytic therapy in pregnancy. J Thromb Thrombolysis 2006; 21: 271-6.

18. Kline JA, Williams GW, Hernandez-Nino J. D-dimer concentrations in normal pregnancy: new diagnostic thresholds are needed. Clin Chem 2005; 51: 825-9.

19. Richter JE. Update on the management of achalasia: balloons, surgery and drugs. Expert Rev Gastroenterol Hepatol 2008; 2: 435-45

20. Khudyak V, Lysy J, Mankuta D. Achalasia in pregnancy. Obstet Gynecol Surv 2006; 61: 207-11.

21. Palanivelu C, Rangarajan M, Maheshkumaar GS et al. Laparoscopic Heller's cardiomyotomy for achalasia of the cardia in a pregnant patient. Ann Acad Med Singapore 2008; 37: 442-3.

22. Khandelwal M, Krueger C. Diaphragmatic hernia after laparoscopic esophagomyotomy for esophageal achalasia in pregnancy. ISRN Gastroenterol 2011; 2011: 871958

Mottatt 4.4. 2013, første revisjon innsendt 25.6. 2013, godkjent 2.10. 2013. Redaktør: Sigurd Høye. 